\title{
Bionanocomposite films developed from corn starch and natural and modified nano-clays with or without added blueberry extract
}

\author{
Tomy J. Gutiérrez*, Vera A. Alvarez \\ Grupo de Materiales Compuestos Termoplásticos (CoMP), Instituto de Investigaciones en Ciencia y Tecnología de Materiales (INTEMA), Facultad de \\ Ingeniería, Universidad Nacional de Mar del Plata (UNMdP) y Consejo Nacional de Investigaciones Científicas y Técnicas (CONICET), Colón 10850, B7608FLC, \\ Mar del Plata, Argentina
}

\section{A R T I C L E I N F O}

\section{Article history:}

Received 29 August 2017

Received in revised form 12 October 2017

Accepted 15 October 2017

Available online 20 October 2017

\section{Keywords:}

Food packaging

Nanopackaging

pH-sensitive bionanocomposite

Thermoplastic starch

\begin{abstract}
A B S T R A C T
Edible and bionanocomposite films were developed by extrusion followed by thermo molding. Corn starch (Zea mays), glycerol, and several nano-clays were used as the carbohydrate polymer, plasticizer and nano-fillers, respectively. Pure blueberry (Vaccinium corymbosum) extract (BE, 100\% anthocyanin), as well as natural and modified montmorillonites (Mnt) with or without BE nano-packaged within their layers were incorporated into the thermoplastic starch (TPS) matrix. Previous studies by our research group have shown that BE, and BE nano-packaged within natural and modified Mnt, are pH-sensitive. With this in mind, we set out to develop edible and intelligent (pH-sensitive) bionanocomposite films with improved properties. Unfortunately however, none of the films formulated were $\mathrm{pH}$-sensitive. All the films showed X-ray diffractograms typical of semicrystalline, albeit largely amorphous, materials coinciding with the morphological observations made under scanning electron microscopy. The results confirmed that total starch gelatinization occurred under the selected extrusion conditions. Films prepared from corn starch containing BE showed a plasticizing effect, giving materials with lower thermal resistance and surface moisture values, which were also more opaque, denser, and rougher. All the nanofillers tested were completely exfoliated within the TPS matrix, except for the natural Mnt that was partly exfoliated and partly intercalated in the matrix. In general, materials containing nano-fillers with a greater degree of interlayer spacing (more exfoliated) showed higher thermal resistance and Young's modulus, but lower strain at break values.
\end{abstract}

๑) 2017 Elsevier Ltd. All rights reserved.

\section{Introduction}

Edible and bionanocomposite films, usually developed from polysaccharides, proteins, lipids and other biopolymers, represent the most promising alternatives to synthetic polymers as packaging materials, thus contributing to the drive to reduce the consumption of these types of plastics (Dai, Chang, Geng, Yu, \& Ma, 2010). According to data published by the Cámara Argentina de la Industria Plástica (Argentine Chamber of the Plastics Industry; CAIP) (CAIP, 2010), Argentina is the largest consumer of plastics in Latin America and occupies the 11th place in the world. In 2007, the CAIP

\footnotetext{
* Corresponding author. Institute of Research in Materials Science and Technology, Faculty of Engineering, National University of Mar del Plata and National Council of Scientific and Technical Research (CONICET), PO Box B7608FLC, Colón 10850, Mar del Plata, Argentina.

E-mail addresses: tomy_gutierrez@yahoo.es, tomy.gutierrez@fi.mdp.edu.ar (T.J. Gutiérrez).
}

recorded an annual consumption of $41 \mathrm{~kg}$ of synthetic plastic per inhabitant in Argentina. This is an alarming number, and contrary to the ideals of environmental conservation which require the use of so-called green materials and technologies. In Argentina, the fields of application of synthetic plastic products are diverse, see Fig. 1 (CAIP, 2010). Packaging, however, represents almost 50\% of the synthetic plastic consumed, a figure comparable to that of many developing countries. This means that reducing the use of synthetic plastics in packaging, especially food packaging, will greatly impact on the national consumption of plastics.

The use of starch as a biopolymeric base material for the development of edible and bionanocomposite films has been widely studied due to its wide availability, low cost, non-toxicity, renewability, biodegradability and capacity to be processed by equipment currently available in the polymer and food industries (Veiga-Santos, Oliveira, Cereda, \& Scamparini, 2007). In spite of these favorable characteristics, starch-based films show two main drawbacks: hydrophilicity and brittleness that still need to be 


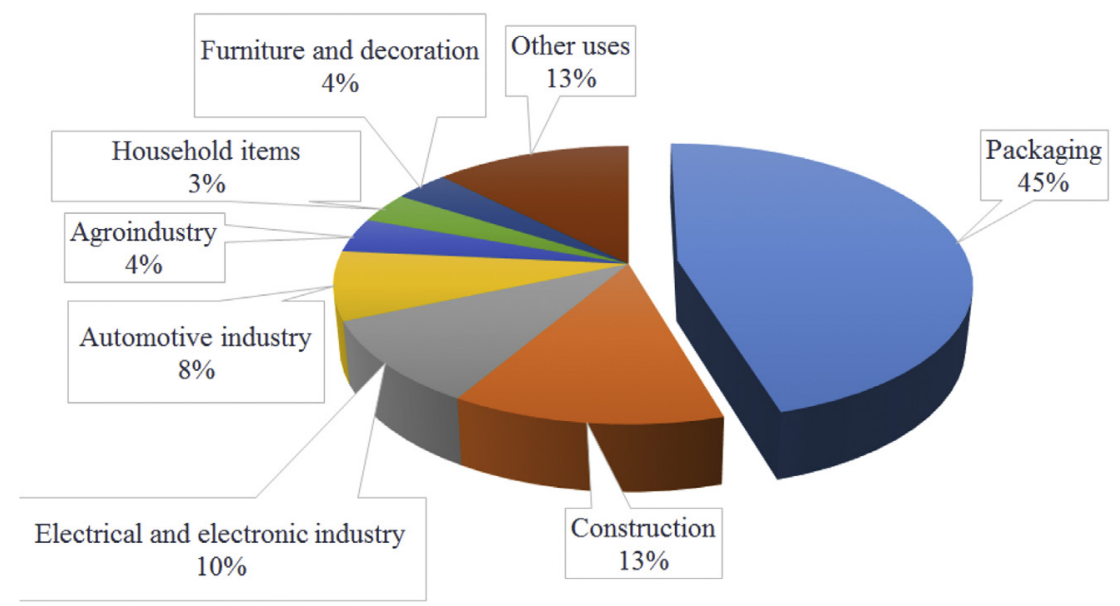

Fig. 1. Diversification by sector or economic activity of the consumption of plastics in Argentina (CAIP, 2010).

overcome before they can be widely applied as food packaging materials (Iman \& Maji, 2012). Nonetheless, special attention has been paid to corn starch (Zea mays) in the development of edible and bionanocomposite films due to their high rates of production worldwide (Gutiérrez, Tapia, Pérez, \& Famá, 2015).

Several alternatives have been proposed to improve the properties of starch films: 1) modifying the starch itself; 2) the use of different plasticizers; 3 ) mixing the starch with other natural or synthetic polymers; 4) the use of food additives; and 5) the addition of natural or modified nano-fillers obtained from clays, cellulose, and/or inorganic nanoparticles (Gutiérrez, González Seligra, Medina Jaramillo, Famá, \& Goyanes, 2017). With regard to this last alternative, several authors have prepared and studied starchbased films made with added natural or modified nano-clays from montmorillonite (Mnt) (Pérez, Pérez, Alvarez, \& Bernal, 2013; Vazquez, Cyras, Alvarez, \& Moran, 2012). However, incorporating pH-sensitive nano-fillers prepared from natural or modified Mnt into starch-based materials in order to develop intelligent films has not yet been done. Our research group recently characterized intelligent ( $\mathrm{pH}$-sensitive) nano-clays obtained from natural or modified Mnt with added blueberry extract (Gutiérrez, Ponce, \& Alvarez, 2017). Gutiérrez, Ponce et al. (2017) reported that Mnt chemically modified with a quaternary ammonium salt (dimethyl dehydrogenated tallow ammonium) produced nano-clays with a higher degree of interlayer spacing, i.e. the nano-clays were more exfoliated. This increased their capacity to nano-pack larger amounts of blueberry extract (100\% anthocyanin) compared to natural nano-clays.

The development of intelligent and edible films has received a great deal of attention from the scientific community as these materials could inform consumers about the state of perishable foods as well as warning them about the presence of contaminants, and/or otherwise adulterated food. This could be a way to reduce the large amount of food that is discarded by consumers which, according to the FAO (2012), could feed all the people currently suffering from hunger in the world today. In the last four years several authors have developed intelligent films by directly incorporating pigments of natural origin, mainly anthocyanins and betalains, into biopolymeric matrices (Yoshida, Maciel, Mendonça, \& Franco, 2014; Luchese, Frick, Patzer, Spada, \& Tessaro, 2015; Pereira, de Arruda, \& Stefani, 2015; Gutiérrez, Guzmán, Medina; Jaramillo, \& Famá, 2016; Choi, Lee, Lacroix, \& Han, 2017; Liu et al., 2017; Ma \& Wang, 2016; Prietto et al., 2017; Luchese, Garrido, Spada, Tessaro, \& de la Caba, 2017). However, there is no record of intelligent nano-clays being used to obtain intelligent, edible and bionanocomposite films with improved properties.

In addition, the intelligent films that have been reported up until now have been prepared by casting (Yan, Hou, Guo, \& Dong, 2012). Although this method is appropriate for preliminary study, it is not feasible on an industrial scale as large amounts of energy are required to evaporate the solvent, and the processes involved in power handling large volumes of film-forming solutions are complex (Gutiérrez \& Alvarez, 2017). Polymer and food manufacturers thus prefer to produce thermoplastic starch (TPS) materials using techniques such as extrusion (Xie et al., 2013), which does not require the use of a solvent as starch gelatinization is achieved by the mechanical (shear force) and thermal energy produced during processing (Alam, Pathania, \& Sharma, 2016; Zhang, Wang, Zhao, \& Wang, 2013). In addition, extrusion is a continuous system that can be managed by only a few operators, thus optimizing the manufacturing process. It is worth noting that starch gelatinization under these conditions is controlled by water diffusion. Since the shear forces destroy the starch granules, water transfer within the biopolymer is much faster (Burros, Young, \& Carroad, 1987). The starch may thus be plasticized with very small amounts of water (16-20\%) reducing subsequent drying requirements (Gutiérrez, Guarás, \& Alvarez, 2017).

Despite the advantages of extrusion, its use in the development of TPS as a food packaging material has been limited. This is possibly because the procedure is more complex for TPS than for other polymers, as its production from native and modified starch involves several transitions such as granule expansion, gelatinization, melting, decomposition and starch retrogradation (starch recrystallization) (Li et al., 2011; von Borries-Medrano, Jaime-Fonseca, \& Aguilar-Méndez, 2016; Xie et al., 2017).

The aim of this study was to develop intelligent ( $\mathrm{pH}$-sensitive) films with improved properties. To this end, we characterized and analyzed the surface, physicochemical and mechanical properties of edible and bionanocomposite films prepared by extrusion from corn starch with incorporated intelligent nano-fillers.

\section{Experimental}

\subsection{Materials}

The edible and bionanocomposite films were prepared from native corn starch (Zea mays) obtained from the Distribuidora Dos Hermanos, Mark Ying Yang (Mar del Plata, Argentina). Glycerol was purchased from Aurum (Mar del Plata, Argentina) and used as the plasticizer. The nano-clays used as nano-fillers in this study were 
natural and modified montmorillonites (Mnt) supplied by Laviosa Chimica Mineraria S.p.A. (Livorno, Italy) and were used as received. According to the manufacturer's descriptions, the modified Mnt is a nano-clay derived from a naturally occurring Mnt, purified and modified with a quaternary ammonium salt (dimethyl dehydrogenated tallow ammonium). This modification was selected based on the fact that it has been extensively studied over a number of years, and the resulting modified nano-clay has been shown to be nontoxic with no risk to human health (Boethling, 1984; Breakwell, Homer, Lawrence, \& McWhinnie, 1995; Kozak \& Domka, 2004). Blueberry (Vaccinium corymbosum) extract ( $100 \%$ anthocyanin) was obtained according to the procedure described by Gutiérrez, Ponce et al. (2017). Briefly, ripe fruits were purchased from a local market in Mar del Plata, Buenos Aires, Argentina. The fruits were selected, discarding any diseased or stained specimens, before weighing out $170 \mathrm{~g}$, crushing and filtering. The residue obtained, mainly the fruit skin, was then washed with $100 \mathrm{~mL}$ of ethanol (Aldrich - product code: 34923$)$. The blueberry extract $(B E)$ was prepared the same day that the nano-clays and the films were developed, and maintained under refrigeration at $5{ }^{\circ} \mathrm{C}$ in a dark container until further processing in order to avoid oxidative damages.

\subsection{Formation of the nano-fillers}

The nano-fillers with added blueberry extract were prepared by mixing $2 \mathrm{~g}$ of nano-clay and $40 \mathrm{~mL}$ of $\mathrm{BE}$. The mixture was then frozen at $-20{ }^{\circ} \mathrm{C}$ for $48 \mathrm{~h}$ after which it was lyophilized at $13.33 \mathrm{~Pa}$ ( $100 \mathrm{mTorr}$ ) and $-50^{\circ} \mathrm{C}$ for $72 \mathrm{~h}$ using a Gland type Vacuum Freeze Dryer, Columbia International, Model FD-1B-50 (Shaan Xi, China) in order to obtain a free flowing product. Lyophilization also preserves the active compounds of the BE and ensures a size of clay particle in the nanometer range. The resultant nano-clays were conditioned in containers with a saturated solution of $\mathrm{NaBr}\left(a_{w} \sim 0.575\right.$ at $\left.25^{\circ} \mathrm{C}\right)$ for seven days before making the edible and bionanocomposite films, in order to maintain controlled and known conditions. During this period the containers were protected from light in a dark room to avoid photodegradation of the pigment. Four types of nano-filler samples were prepared as follows: natural Mnt (NMnt), natural Mnt with added BE (NMntBE), modified Mnt (MMnt) and modified Mnt with added BE (MMntBE). These nano-fillers have already been exhaustively characterized by our research group in Gutiérrez, Ponce et al. (2017).

\subsection{Film formation and extrusion conditions}

Edible and bionanocomposite films were prepared from native corn starch using a 1:1.4 (w/w) ratio (glycerol:starch). To evaluate the effect of each filler used (BE, NMnt, NMntBE, MMnt and MMntBE), $4 \% \mathrm{w} / \mathrm{w}$ of each was added to the starch content of each film system, maintaining the same glycerol:starch ratio. This percentage was employed based on previous studies carried out by our research group (Ludueña, Morán, \& Alvarez, 2015; Vazquez et al., 2012). Each system was then pre-blended manually until homogeneous mixtures were obtained. The mixtures were then processed by extrusion in a twin screw extruder with six heating zones. The temperature profile used was 90/100/105/110/120/ $120{ }^{\circ} \mathrm{C}$ with a screw rotation speed of $30 \mathrm{~Hz}$. After processing, the materials obtained from the extruder were allowed to cool to room temperature $\left(25^{\circ} \mathrm{C}\right)$ before being pelletized using an automatic pelletizer (Weinuo Technology Co., Ltd, Jiangsu, China). The pelletized materials ( $13 \mathrm{~g}$ ) were then hot-pressed using a hydraulic press at $130{ }^{\circ} \mathrm{C}$ and $1 \times 10^{7} \mathrm{~Pa}$ (100 bar) for $20 \mathrm{~min}$, after which a cooling cycle was applied until they reached a temperature of $30^{\circ} \mathrm{C}$. The six resulting materials were: thermoplastic starch (TPS), TPS + blueberry extract (TPS + BE), TPS + NMnt, TPS + NMntBE,
TPS + MMnt, and TPS + MMntBE. The prepared films were then conditioned at a controlled relative humidity $(\sim 57 \%)$ for a week at $25{ }^{\circ} \mathrm{C}$ before characterization.

\subsection{Film characterization}

\subsubsection{X-ray diffraction (XRD)}

$X$-ray diffractograms of the different films were obtained with a PAN analytical X'Pert PRO diffractometer (Netherlands) equipped with a monochromatic $\mathrm{Cu} \mathrm{K}_{\alpha}$ radiation source $(\lambda=1.5406 \AA)$ operating at a voltage of $40 \mathrm{kV}$ and current $40 \mathrm{~mA}$ at a scanning rate of $1^{\circ} / \mathrm{min}$. The scanning region of the samples was in a $2 \theta$ range between $3^{\circ}$ and $33^{\circ}$. The distances between the planes of the crystals $d(\AA)$ were calculated from the diffraction angles $\left(^{\circ}\right)$ measured from the X-ray diffractograms according to Bragg's law:

$n \lambda=2 d \sin (\theta)$

where $\lambda$ is the $\mathrm{Cu} \mathrm{K}$ radiation wavelength and $n$ is the order of reflection. For the calculations, $n$ was taken as 1 . The thicknesses of the samples on the slides were $\sim 0.90 \mathrm{~mm}$.

\subsubsection{Thermogravimetric analysis (TGA)}

A thermal analyzer (Model TGA Q500, Hüllhorst, Germany) was used to carry out the thermogravimetric tests. Samples were heated at a constant rate of $10^{\circ} \mathrm{C} / \mathrm{min}$ from room temperature up to $600^{\circ} \mathrm{C}$ under a nitrogen flow of $30 \mathrm{~mL} / \mathrm{min}$. Film weights were in the range of $16-20 \mathrm{mg}$. Three replicates per sample were analyzed to ensure repeatability. The weight loss of the materials was recalculated on dry basis and the different degradation phases noted. Standard deviations (SD) were lower than $1 \%$ for all the systems tested, and the representative curves of each one were reported.

\subsubsection{Surface moisture}

A Moisture Analyzer, Model MA150 (Goettingen, Germany) was used to estimate the surface moisture content of the films. Square shaped samples $(2 \mathrm{~cm} \times 2 \mathrm{~cm})$ were dried at $105{ }^{\circ} \mathrm{C}$ for $120 \mathrm{~s}$. Measurements were then conducted in triplicate for each film and the results were reported as the $\%$ of average surface moisture \pm SD.

\subsubsection{Atomic force microscopy (AFM)}

An Agilent 5500 in the Acoustic AC Mode (AAC Mode) with silicon nitride $\left(\mathrm{Si}_{3} \mathrm{~N}_{4}\right)$ tips and a cantilever oscillation frequency of $155 \mathrm{kHz}$ was used to obtain topographic images of the films. The tips were $2 \mathrm{~mm}$ long and $\mathrm{V}$-shaped with a spring constant of $0.2 \mathrm{~N} \mathrm{~m}^{-1}$, and were positioned over the sample under ambient conditions. The AFM images were taken at the center and periphery of the surface of the films. Surfaces exposed to the thermocompression process were also analyzed in terms of their average roughness ( $\mathrm{Ra}$ ). The AFM images were processed with PicoView image software.

\subsubsection{Contact angle}

The contact angles $(\theta)$ of the thermo-compressed films were determined by carefully dropping one drop of distilled water $(2 \mu \mathrm{L})$ onto the thermo-compressed film surfaces using a syringe (KDL Corp., Shanghai, China) and then quickly measuring the contact angles before swelling started with a Ramé-Hart instrument (contact angle goniometer) model 100-25-4 (Mountain Lakes, New Jersey, USA) equipped with drop image advanced software, at $0.0001^{\circ}$ precision, under ambient conditions i.e. air atmosphere at $25^{\circ} \mathrm{C}$. Contact angles were then calculated from the intersection of the liquid-solid interface (drop of water-surface of the film) and the liquid-vapor interface (tangent to the boundary of the drop) (Gutiérrez \& González, 2017). The contact angles were expressed as 
the average of 12 measurements per film \pm SD. A representative image of each film system was also taken.

\subsubsection{Scanning electron microscopy (SEM)}

A JEOL JSM-6460 LV scanning electron microscope was used to analyze both the surfaces and the cryo-fractured surfaces of the thermo-compressed films. Samples were cryo-fractured by freezing them in liquid nitrogen and their morphologies were then observed in the fracture cross-section of the film. For both analyses films were mounted on bronze stubs and sputter-coated (Sputter coater SPI Module, Santa Clara, CA, USA) with a thin layer of gold for $35 \mathrm{~s}$, and observed with an accelerating voltage of $15 \mathrm{kV}$ at a magnification of $1 \mathrm{kX}$.

\subsubsection{Determination of film thickness (e)}

The thickness (e) of each starch film was determined by measuring samples at eighteen different locations per sample using a micrometer (Liuling, Shanghai, China) with an accuracy of $\pm 0.001 \mathrm{~mm}$. Results were reported as mean values \pm SD.

\subsubsection{Density $(\rho)$}

Sample discs ( $12 \mathrm{~mm}$ diameter - $\emptyset$ ) from each film system were used for density $(\rho)$ determination. The film discs were weighed $\left(\mathrm{W}_{\mathrm{i}}\right)$, dried at $105^{\circ} \mathrm{C}$ for $24 \mathrm{~h}$, and weighed $\left(\mathrm{W}_{\mathrm{f}}\right)$ again. The density was then calculated as the ratio between the weight (W) and volume $(\mathrm{V})$ where the volume is equal to thickness $(e) \mathrm{x}$ area $(\mathrm{A})$ of each disc using the following Eq. (2):

$\rho=\mathrm{w}_{/ \mathrm{V}}=\mathrm{W}_{/ \mathrm{A} * e}=\mathrm{W}_{\mathrm{i}}-\mathrm{W}_{\mathrm{f}} /\left(\frac{\emptyset}{2}\right)^{2} * \Pi * e$

The density experiments were undertaken in triplicate, and the data reported as mean values $\pm \mathrm{SD}$.

\subsubsection{Opacity}

The opacity was determined by the procedure described by Sukhija, Singh, and Riar (2016). The ultraviolet (UV) and visible light barrier properties of dried films were measured using a UV-Vis spectrophotometer (u-2001, Japan) at selected wavelengths between 400 and $800 \mathrm{~nm}$. Film opacity was then measured at $600 \mathrm{~nm}$ and calculated using the following equation given by Han and Floros (1997):

Opacity $=\mathrm{A}_{600 / e}$

where: $\mathrm{A}_{600}=$ the absorbance at $600 \mathrm{~nm}$ and " $e$ " = film thickness $(\mathrm{mm})$.

\subsubsection{Uniaxial tensile tests}

An INSTRON 4467 machine was used to generate the forcedistance curves following the ISO 527-2 (2012) norm. The mechanical properties of the films were determined from at least 10 samples, which were previously cut in a bone-shape with an effective area of $\sim 28.6 \mathrm{~mm}$ long $\times \sim 5.5 \mathrm{~mm}$ width and crosssectional area $\sim 6.5 \mathrm{~mm}^{2}$ (the exact values differed slightly between samples). Samples were mounted and clamped with tensile grips (A/TG model), and then stretched at a constant speed of $0.01 \mathrm{~mm} / \mathrm{s}$ at $25{ }^{\circ} \mathrm{C}$ until they broke. The mechanical properties at break: maximum stress $\left(\sigma_{m}\right)$ and strain at break $\left(\varepsilon_{b}\right)$, were obtained from the stress-strain curves. For this, the stress-distance curves were transformed into stress-strain curves as outlined in ISO 527-2 (2012). Young's modulus (E) was then determined from the linear regression slope of the stress-strain curves, and toughness $(T)$ was calculated from the area underneath them.

\subsubsection{Response to $\mathrm{pH}$ changes}

In order to evaluate the responses of the films to $\mathrm{pH}$ changes circular samples ( $12 \mathrm{~mm}$ diameter) of each film system were placed in solutions at pHs of 1,7 and 13 , prepared from $\mathrm{NaOH}(0.1 \mathrm{M})$ and $\mathrm{HCl}(0.1 \mathrm{M})$. Film response was then evaluated from images taken with an 8.1 mega pixel Cyber-shot Sony camera; model DSC-H3 (Tokyo, Japan).

\subsection{Statistical analysis}

Analyses of variance (ANOVA) using OriginPro 8 (Version 8.5, Northampton, USA) software were employed to analyze the data, and the results were shown as mean values \pm SD. Differences between the mean values of the measured properties were compared using a multiple-range Tukey's test. A significance level of 0.05 was used.

\section{Results and discussion}

It should be noted before starting this section that for a better understanding of the results, they are reported as follows: 1) the effect of incorporating the blueberry extract (BE) into the TPS matrix; 2) the effect of the natural and modified nano-fillers without the BE between their layers (NMnt and MMnt); 3) the effect of the natural and modified nano-fillers with the BE nano-packaged between their layers (NMntBE and MMntBE); and 4) a comparative study of the four nano-clays used as fillers in this study (NMnt, MMnt, NMntBE and MMntBE).

\subsection{X-ray diffraction $(X R D)$}

Fig. 2 shows the X-ray diffractograms of the films studied. This study was performed primarily to investigate the dispersion of the nano-fillers within the TPS matrix. All the films showed X-ray diffractograms typical of a semicrystalline material, i.e. they were mainly amorphous with a weak crystalline phase. Similar results have been reported in the literature by other authors for starchbased films (Abreu et al., 2015; Slavutsky, Bertuzzi, \& Armada, 2012; Wilpiszewska, Antosik, \& Spychaj, 2015).

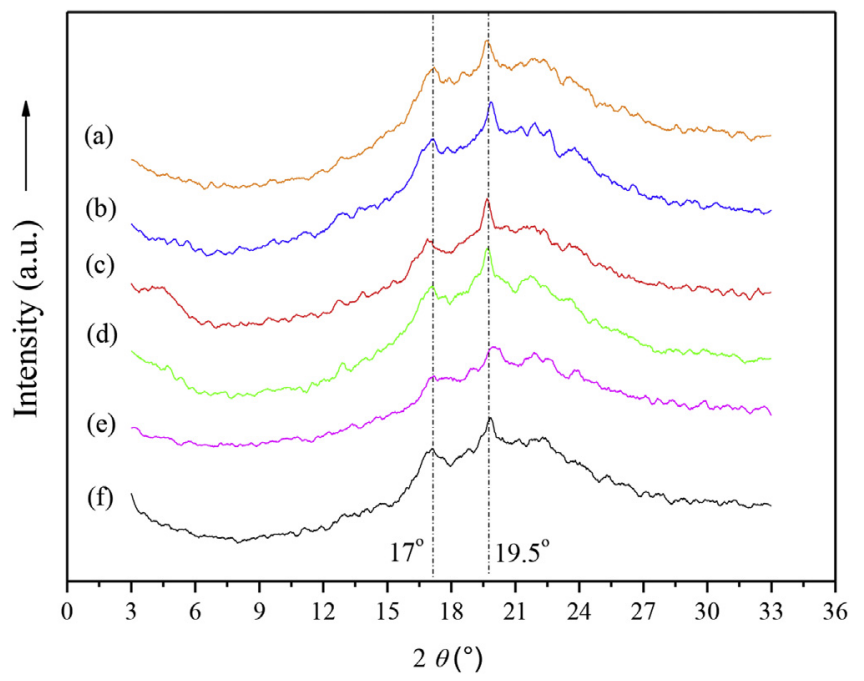

Fig. 2. X-ray diffraction diffractograms of the films studied: (a) thermoplastic starch (TPS), (b) TPS + blueberry extract (TPS + BE), (c) TPS + natural montmorillonite (TPS + NMnt), (d) TPS + natural montmorillonite containing blueberry extract (TPS + NMntBE), (e) TPS + modified montmorillonite (TPS + MMnt), and (f) TPS + modified montmorillonite containing blueberry extract (TPS + MMntBE). 
The characteristic peaks of the crystalline phase of the starch were observed at $2 \theta=17^{\circ}$ and $19.5^{\circ}$ corresponding to the $d$-spacings $\cong 5.2 \AA$ and $4.6 \AA$, respectively. This type of diffraction pattern is typical of films prepared from cereal starches (A-type structure) (Vasanthan \& Hoover, 1992) and was thus expected for the corn starch used in this study. According to García-Tejeda et al. (2013) the signal observed for $2 \theta=17^{\circ}$ corresponding to $d$-spacing $\cong$ $5.2 \AA$ is associated with interactions between the short external amylopectin chains and the glycerol. The peaks with $d$-spacing $\cong$ $4.5 \AA$ observed in the films correspond to a V-type structure (Gutiérrez \& González, 2016).

Diffraction peaks ranging between $3^{\circ}$ and $6^{\circ}$ are associated with the interlayer spacing $\left(d_{001}\right)$ of nano-clays within the TPS matrix (Gutiérrez, Ponce, et al., 2017). The presence of the diffraction peak at $4.4^{\circ}(20.1 \AA)$ for the TPS + NMnt film reveals that the NMnt nanofiller underwent exfoliation (expansion of its layers) during extrusion, since it showed a diffraction peak at $4.8^{\circ}$ (18.6 $\AA$ ) before this process occurred (Gutiérrez, Ponce, et al., 2017). The location of this diffraction peak also indicates that the NMnt nano-filler is partly intercalated, and that only some starch chains were incorporated between the interlayer spacings of the nano-filler. In contrast, the absence of diffraction peaks between $3^{\circ}$ and $6^{\circ}$ for the TPS + NMntBE, TPS + MMnt, and TPS + MMntBE films indicates that these nano-fillers were successfully exfoliated within the TPS matrix. This study thus demonstrates that the extrusion process guarantees the exfoliation of the nano-clays used as fillers. It should be noted that a greater degree of exfoliation of the nano-clays within the matrix results in more nano-filler/starch interactions and fewer starch-starch interactions (Slavutsky et al., 2012).

\subsection{Thermogravimetric analysis (TGA)}

The TGA curves of the six film systems evaluated can be seen in Fig. 3. According to the literature, this type of material show three main stages of thermal degradation that occur in the following order: 1) from $100{ }^{\circ} \mathrm{C}$ the water absorbed from the environment and the available (free) water inside the material is evaporated; 2 ) at $290{ }^{\circ} \mathrm{C}$ the glycerol rich phase is evaporated; and 3) at $330^{\circ} \mathrm{C}$ the maximum thermal degradation of the starch rich phase is often observed (Gutiérrez, Morales, Pérez, Tapia, \& Famá, 2015; Gutiérrez, Suniaga, Monsalve, \& García, 2016). It has been generally established that the thermal degradation mechanism of the starch rich phase of these materials consists of the elimination of the polyhydroxyl groups accompanied by the depolymerization and decomposition of the starch matrix, and finally the production of carbon (Zeppa, Gouanvé, \& Espuche, 2009). The results obtained here showed a maximum loss of moisture at $144{ }^{\circ} \mathrm{C}$ for all the films evaluated. The evaporation temperature of the glycerol rich phase and the decomposition temperature of the starch rich phase (around $278{ }^{\circ} \mathrm{C}$ and $320{ }^{\circ} \mathrm{C}$, respectively) were slightly lower compared to the values reported in the literature (see DTGA (derivative TGA) curves, appendix A). It is worth noting that the stage corresponding to the loss of moisture was not observed in the TGA curves (Fig. 3). This is because the weight loss of the systems was recalculated on dry basis in order to avoid distortions as a result of the variable moisture content of the films.

It can be seen from Fig. $3 \mathrm{~A}$ that the addition of $\mathrm{BE}$ within the thermoplastic starch (TPS) matrix resulted in a lower thermal resistance compared to the pure TPS film. This type of behavior has generally been associated with the plasticizing effect of the polyphenolic extracts. It is worth remembering that $\mathrm{BE}$ is made up of $100 \%$ anthocyanins which are natural polyphenolic pigments. Similar results have been reported by Medina Jaramillo, Gutiérrez, Goyanes, Bernal, \& Famá, (2016) for films prepared from cassava starch with the addition of different concentrations of yerba mate extract. The plasticizing effect has been associated with the reduction of intra- and intermolecular interactions (hydrogen bonding) between the starch chains, and the formation of hydrogen bonds between the polyphenolic extracts and the starch matrix. The latter enables the lubrication of the macromolecular starch chains, thus allowing their molecular rearrangement within the material and the sliding of the parallel planes against each other (Mali, Grossmann, Garcia, Martino, \& Zaritzky, 2002).

As a general rule it has been assumed that adding clay nanofillers increases the thermal resistance of bionanocomposite starch materials (Pandey \& Singh, 2005). However, there are few studies that take into account the surface effects of nano-fillers and the degree of interlayer spacing. In this study, the addition of the NMnt and MMnt nano-fillers to the TPS matrix led to a lower thermal resistance in these materials (TPS + NMnt and TPS + MMnt compared to the TPS film) (Fig. 3B). This behavior appears to be largely related to steric hindrance of the intramolecular interactions of the hydrogen bonds between the starch chains caused by the nano-clays. The nano-clays thus act as an impediment to interactions between the starch chains. This effect was more significant in the TPS + NMnt film than in the TPS + MMnt film. It can thus be assumed that the greater degree of interlayer spacing in the MMnt nano-filler compared to that of the NMnt nano-filler permitted the starch chains to pass more effectively between these layers (the exhaustive characterization of the nano-fillers used in this study is published in Gutiérrez, Ponce et al. (2017)). Thus, the starch chains interacted more strongly with each other in the presence of the MMnt nano-filler compared to the NMnt nanofiller, and the hydrogen bonds between the starch-starch molecules interacted less. The behavior described above was also observed in the TPS + NMntBE and TPS + MMntBE films when compared to the TPS film (Fig. 3C). We can thus conclude from Fig. 3B and C that the addition of the nano-fillers used reduced the thermal resistance of the materials tested.

Fig. 3D shows the TGA curves of all the film systems containing the nano-fillers. The first point to highlight is that the thermal resistance was higher in the films containing the modified nanofillers (TPS + MMnt and TPS + MMntBE) compared to the films containing the natural nano-fillers (TPS + NMnt and TPS + NMntBE). This is most evident when looking at the DTGA curves (see appendix A). This phenomenon is closely related to the greater degree of interlayer spacing in the systems containing the modified nano-fillers, such that a positive relationship between interlayer spacing and thermal degradation resistance was observed. Thus a second conclusion that can be drawn from the TGA tests is that greater interlayer spacing of the nano-clay fillers, led to stronger interactions between these nano-fillers and the starch molecules. These results agree with the XRD results.

\subsection{Surface moisture}

Table 1 shows the surface moisture contents of the different films studied. It is well known that the molecular interactions occurring within the starch films affect the physicochemical and structural behavior of the surface of these materials: surface moisture content, surface morphological characteristics (average roughness (Ra) and mean square roughness (Rq)), as well as their surface properties (total surface energy $\left(\gamma_{s}\right)$, and dispersive $\left(\gamma_{s}^{d}\right)$ and polar $\left(\gamma_{s}^{P}\right)$ components) (Gutiérrez \& González, 2016, 2017; Gutiérrez, Suniaga, et al., 2016; Gutiérrez, 2017a). By surface moisture content, we mean water molecules that are physisorbed in the first layers of a material when this is exposed to an environment with a certain relative humidity.

The TPS + BE film had a lower surface moisture content than the TPS film (Table 1). This behavior is in line with the possible 

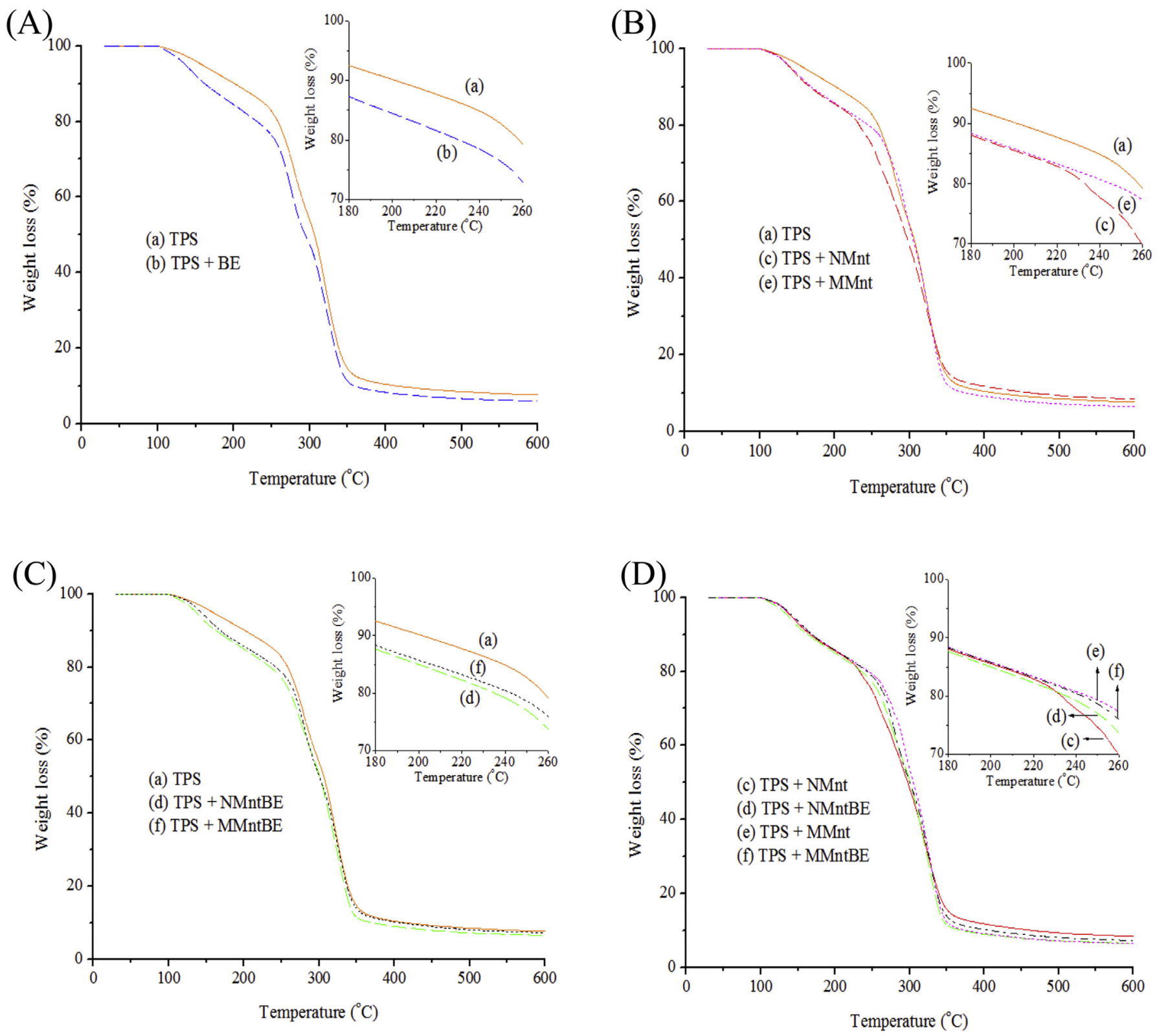

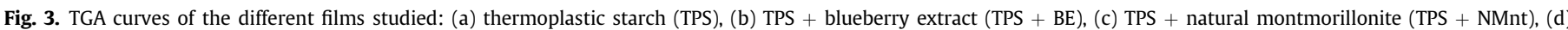

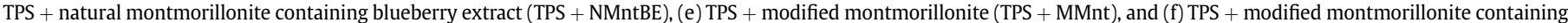
blueberry extract (TPS + MMntBE).

Table 1

Surface moisture, contact angle, thickness $(e)$, density $(\rho)$, and opacity of the different films.

\begin{tabular}{|c|c|c|c|c|c|c|}
\hline Parameter & TPS & $\mathrm{TPS}+\mathrm{BE}$ & TPS + NMnt & TPS + NMntBE & TPS + MMnt & TPS + MMntBE \\
\hline Surface moisture (\%) & $2.8 \pm 0.1^{\mathrm{d}}$ & $1.84 \pm 0.06^{\mathrm{b}}$ & $2.63 \pm 0.06^{c}$ & $1.89 \pm 0.04^{b}$ & $1.4 \pm 0.2^{\mathrm{a}}$ & $1.6 \pm 0.2^{\mathrm{a}, \mathrm{b}}$ \\
\hline Contact angle $\left({ }^{\circ}\right)$ & $80 \pm 6^{\mathrm{d}}$ & $35 \pm 1^{\mathrm{c}}$ & $31 \pm 2^{\mathrm{a}}$ & $32 \pm 1^{\mathrm{b}, \mathrm{a}}$ & $27 \pm 2^{a}$ & $30 \pm 2^{a}$ \\
\hline$e(\mathrm{~mm})$ & $0.97 \pm 0.05^{\mathrm{a}}$ & $0.87 \pm 0.05^{\mathrm{a}}$ & $0.86 \pm 0.06^{\mathrm{a}}$ & $0.86 \pm 0.06^{\mathrm{a}}$ & $0.86 \pm 0.07^{\mathrm{a}}$ & $0.97 \pm 0.07^{\mathrm{a}}$ \\
\hline$\rho\left(\mathrm{g} / \mathrm{cm}^{3}\right)$ & $0.98 \pm 0.05^{\mathrm{a}}$ & $1.13 \pm 0.02^{\mathrm{b}}$ & $1.15 \pm 0.01^{\mathrm{c}, \mathrm{b}}$ & $1.20 \pm 0.04^{\mathrm{d}}$ & $1.1 \pm 0.1^{\mathrm{a}, \mathrm{b}, \mathrm{c}, \mathrm{d}}$ & $1.09 \pm 0.03^{b}$ \\
\hline Opacity & $0.094 \pm 0.001^{\mathrm{a}}$ & $0.133 \pm 0.001^{\mathrm{e}}$ & $0.123 \pm 0.001^{\mathrm{d}}$ & $0.123 \pm 0.001^{\mathrm{d}}$ & $0.119 \pm 0.001^{c}$ & $0.112 \pm 0.001^{b}$ \\
\hline
\end{tabular}

Equal letters in the same row indicate no statistically significant differences $(\mathrm{p} \leq 0.05)$.

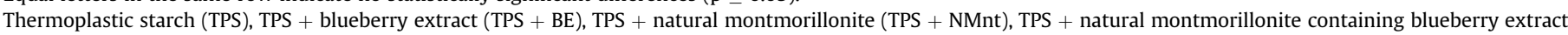
(TPS + NMntBE), TPS + modified montmorillonite (TPS + MMnt) and TPS + modified montmorillonite containing blueberry extract (TPS + MMntBE).

plasticizing effect observed from the TGA results for this same film system (TPS + BE). Medina Jaramillo, González Seligra, Goyanes, Bernal, \& Famá (2015) reported similar results for films with added yerba mate extract. It has been suggested in the literature that hydrogen bonding interactions between the polyphenolic extracts, polyols, and sugars with the starch matrix result in the compensation of the induced charges within these molecules. This reduces their polarity and thus their susceptibility to absorb 
moisture from the environment (Talja, Helén, Roos, \& Jouppila, 2007; Gutiérrez, Suniaga, et al., 2016).

The surface moisture contents of all the bionanocomposite films $($ TPS + NMnt, TPS + NMntBE, TPS + MMnt, and TPS + MMntBE) also had lower values than the TPS film. The nano-fillers used thus produced a reduction in the hydrophilic character of the film surfaces, regardless of whether or not they contained nano-packed BE. The reduction of water sensitivity in starch-based materials resulting from the addition of nano-clays as fillers has been widely reported (Cyras, Manfredi, Ton-That, \& Vázquez, 2008).

In addition, the TPS + NMntBE film showed a statistically significant reduction $(\mathrm{p} \leq 0.05)$ in the surface moisture content compared to the TPS + NMnt film. One could speculate that the BE nano-packed between the layers of the nano-filler improved nanofiller/matrix compatibility since, as has been discussed previously, the BE acts as a plasticizing agent. However, no statistically significant differences ( $p \geq 0.05$ ) were observed between the TPS + MMnt and the TPS + MMntBE films.

The hydrophilic character of the bionanocomposite film surfaces was also lower in systems containing the modified nano-filler (TPS + MMnt) compared to those with the natural nano-filler (TPS + NMnt). This shows the heightened effect of the selected modification for the nano-filler in lowering the surface hydrophilicity of the films.

It should also be noted that the degree of interlayer spacing of the used nano-fillers was negatively correlated with surface moisture content, i.e. nano-fillers with wider interlayer spacings (more exfoliated) produced more hydrophobic bionanocomposite films at the surface level. Probably, stronger nano-filler/starch interactions and weaker starch-starch interactions within the material, as a consequence of the increase in the contact area between the nano-filler and the TPS matrix, resulted in materials with more hydrophobic surfaces. It is important to clarify that the surface modifications of the nano-fillers used have a substantial influence on the compatibility of the bionanocomposite, and this in turn affects the macroscopic surface properties of the said material (Gutiérrez \& Alvarez, 2017). It should not, therefore, be taken as a universal rule that wider interlayer spacing will always lead to a reduction in the hydrophilicity of TPS films, since opposite trends could be observed if the nano-filler/starch interactions are different.

\subsection{Atomic force microscopy (AFM)}

Fig. 4 shows the 2D and 3D topographical images of the different films analyzed by AFM. Average roughness (Ra) was also determined from the AFM images of the films, with values of $25,80,1.5$, 80, 2.5, and $70 \mathrm{~nm}$ for the TPS, TPS + BE, TPS + NMnt, TPS + NMntBE, TPS + MMnt, and TPS + MMntBE films, respectively. A significant increase in Ra was observed in the TPS + BE film $(80 \mathrm{~nm})$ compared to the TPS film $(25 \mathrm{~nm})$. Medina Jaramillo et al. (2015) reported a similar trend in Ra values when incorporating different concentrations of yerba mate extract into cassava starch films. The authors attributed these differences to the plasticizing

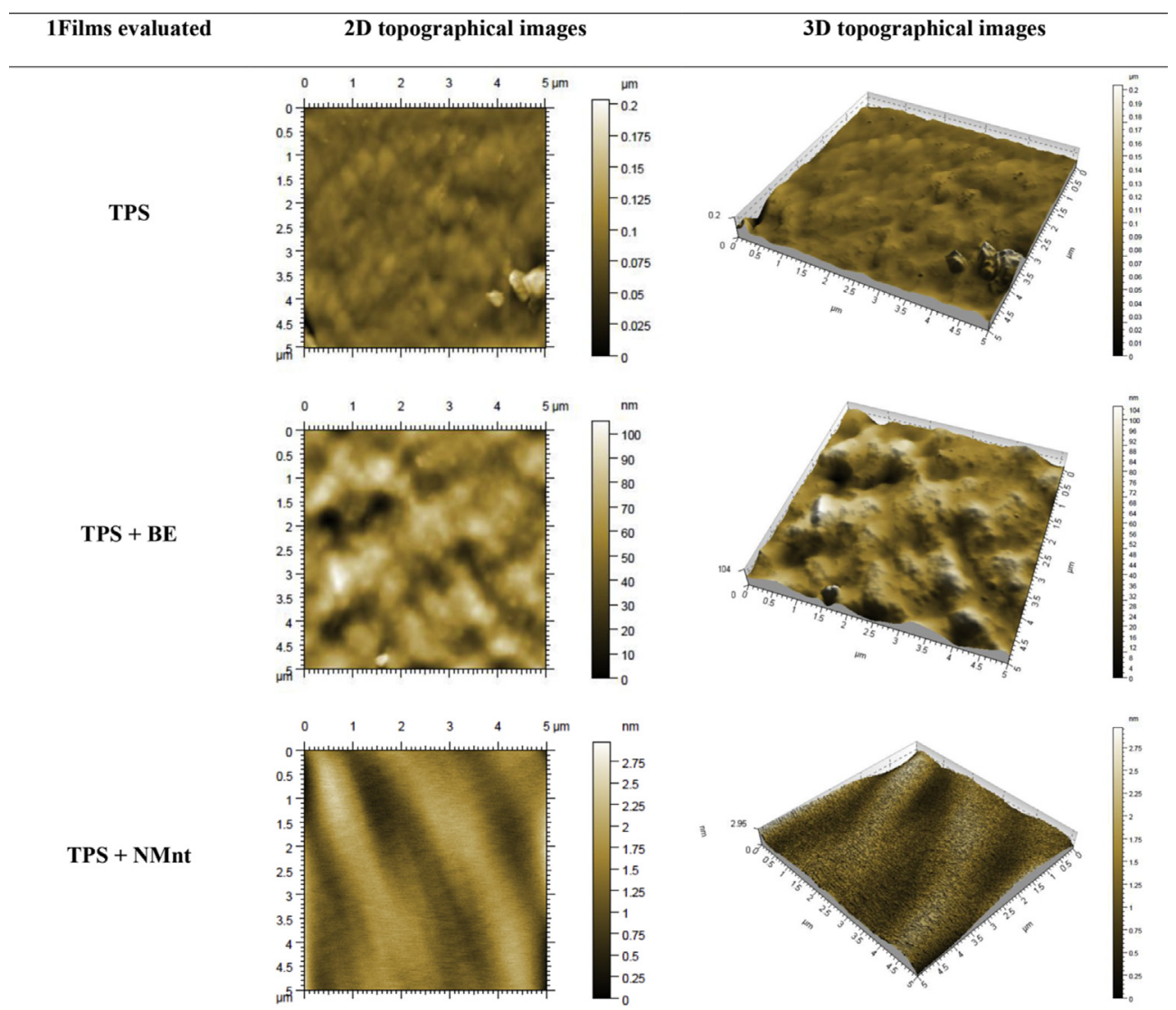

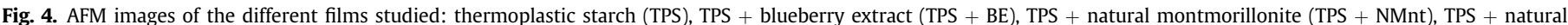

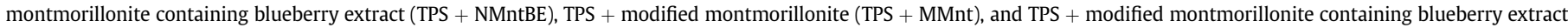
$(\mathrm{TPS}+\mathrm{MMntBE})$ 
effect of the polyphenolic extract. This agrees with the results reported here. In addition, the presence of physical obstacles to the adsorption of moisture from the environment generated by the increase in roughness could partially explain the lower surface moisture content of the TPS + BE film compared to the TPS film.

According to Rhim (2011) the surface Ra of agar films increased linearly with increasing nano-clay content up to $10 \%$ and then stabilized. The opposite effect was, however, observed in this study for the NMnt and MMnt nano-clays (TPS + NMnt - $1.5 \mathrm{~nm}$, and TPS + MMnt $-2.5 \mathrm{~nm}$ ) used as fillers in the TPS matrix (TPS $25 \mathrm{~nm}$ ). This is likely to be related to the hydrogen bond interactions between the nano-fillers and the starch. Hydrogen bond interactions oppose inter- and intramolecular hydrogen bonding interactions of the starch-starch molecules thus preventing twisting (torsional) forces occurring within the starch macromolecules. According to Gutiérrez and González (2016) these torsional forces generate holes similar to craters in the surface (thus their prevention will result in a smoother surface). This is in line with that discussed in previous sections.

No significant differences ( $p \geq 0.05$ ) in the Ra values were found between the TPS + NMnt (1.5 nm) and TPS + MMnt $(2.5 \mathrm{~nm})$ films. This suggests that modifying the nano-filler (organo-clay, MMnt) did not cause significant changes at the superficial level in the developed bionanocomposite films. This was observed even when using nano-fillers with BE nano-packed between their layers (NMntBE and MMntBE).

On the other hand, the TPS + NMntBE and TPS + MMntBE films (with nano-packed $\mathrm{BE}$ ) had greater Ra values than their analogous films, TPS + NMnt and TPS + MMnt (without nano-packed BE). According to previous results published by our research group
(Gutiérrez, Ponce, et al., 2017), the BE nano-packaged in the nanofillers can migrate to the environment, thus diffusing within the TPS matrix and acting as a plasticizer. This would result in films with a behavior similar to the TPS + BE film, where Ra increased as a result of the plasticizing effect caused by the $\mathrm{BE}$.

\subsection{Contact angle}

Table 1 shows the water contact angle values of the films studied. In general, the water contact angle is a good indicator of the degree of surface hydrophilicity or hydrophobicity of a polymeric material (Ojagh, Rezaei, Razavi, \& Hosseini, 2010), and it is widely accepted that higher water contact angle values denote more hydrophobic surfaces (Abreu et al., 2015; Aouada, Mattoso, \& Longo, 2013; Kampeerapappun, Aht-ong, Pentrakoon, \& Srikulkit, 2007; Rhim, 2011; Romero-Bastida et al., 2016; Wilpiszewska et al., 2015). However, the water contact angle depends not only on surface hydrophilicity but also other factors such as: 1) the surface energy of the material; 2) the dispersant $\left(\gamma_{s}^{d}\right)$ and polar $\left(\gamma_{s}^{P}\right)$ components of the surface energy; 3 ) the test atmosphere; 4 ) the distribution of Lewis sites (polar sites); 5) the molecular interactions occurring below the surface, i.e. within the material; 6) the accessibility of the Lewis sites on the surface; 7) the compatibility between the constituents of the plastic material; 8) possible phase separation; 9) the formation (cross-linking reactions) and breaking (depolymerization) of covalent bonds within the polymer matrix; and 10) the roughness of the material (Du, Freysz, \& Shen, 1994a, 1994b; Du, Superfine, Freysz, \& Shen, 1993; Gutiérrez \& González, 2016; Gutiérrez, 2017a; Karbowiak, Debeaufort, Champion, \& Voilley, 2006; Lee, McCammon, \& Rossky, 1984;

TPS + NMntBE
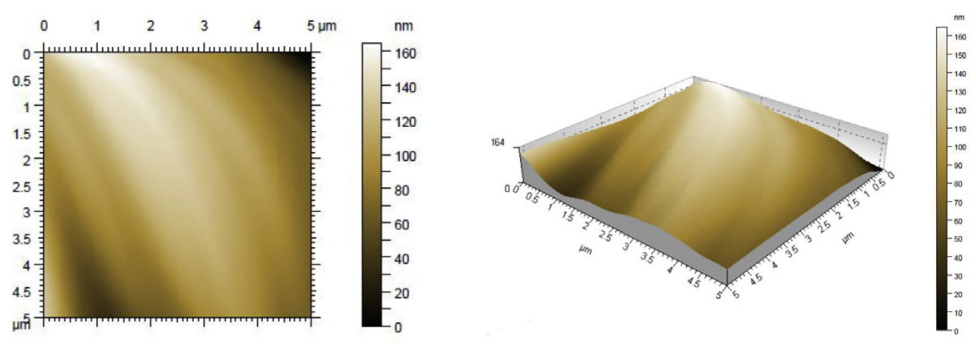

TPS + MMnt
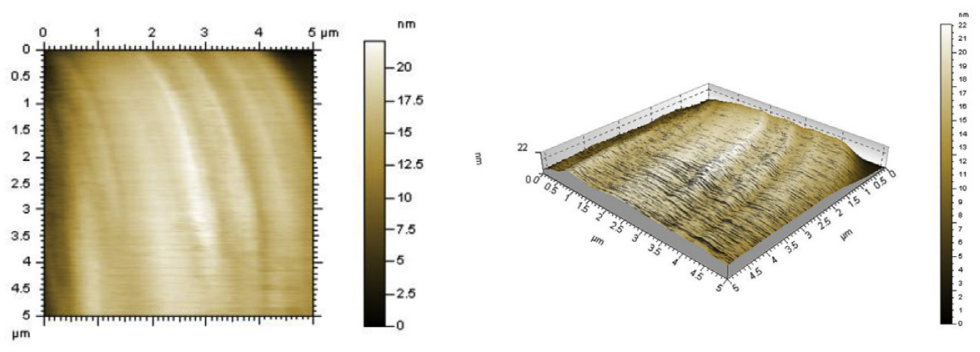

TPS + MMntBE
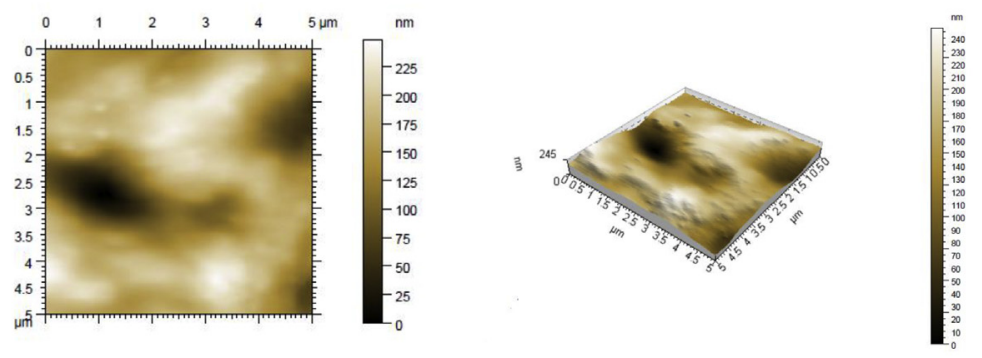

Fig. 4. (continued). 
Vogler, 1998; Vogler et al., 1995).

The TPS + BE film had a lower water contact angle $\left(35 \pm 1^{\circ}\right)$ than the TPS film $\left(80 \pm 6^{\circ}\right)$. It would appear then, that the surface hydrophilicity of the TPS + BE film was greater than that of the TPS film. However, the surface moisture values reported in this study indicate the opposite making the water contact angle results difficult to explain with current knowledge. More in depth trials should be thus carried out in order to clarify this apparent anomaly. For example, surface energy, and the $\gamma_{s}^{d}$ and $\gamma_{s}^{P}$ components of surface energy should be determined, since the surface energy may be enough to achieve the collapse of the water drop on the surface of the material, even when this surface is hydrophobic (Gutiérrez, Ollier, \& Alvarez, 2018). This could explain the lower water contact angle value in the TPS + BE films compared to the TPS film.

Similarly, the incorporation of any of the nano-fillers used within the TPS matrix decreased the water contact angle values. Comparable results were reported by Rhim (2011), Abreu et al. (2015), and Romero-Bastida et al. (2016). However, conflicting results have also been reported by Aouada et al. (2013) and Wilpiszewska et al. (2015), and in no case the behavior of this type of material has been well explained.

No statistically significant differences ( $p \geq 0.05$ ) were observed between the films containing the natural nano-filler (TPS + NMnt) and those with the modified nano-filler (TPS + MMnt), i.e. the modification of the nano-filler did not produce significant changes to the water contact angle values of the bionanocomposite films. This was also observed for the nano-fillers with the nano-packed BE.

In addition, there were no statistically significant differences ( $p \geq 0.05$ ) between the films containing nano-fillers without BE within their layers (TPS + NMnt and TPS + MMnt), and their analogous films with BE (TPS + NMntBE and TPS + MMntBE). This means that neither the modification of the nano-clays used as fillers nor the BE nano-packed within them significantly affected the water contact angles. Kampeerapappun et al. (2007) reported a similar behavior for cassava starch/montmorillonite composite films.

\subsection{Scanning electron microscopy (SEM)}

Fig. 5 shows the SEM micrographs of the thermo-compressed surfaces, and the water contact angle measurements of the films studied. The surface morphology of the bionanocomposite films studied was consistent with the AFM results (see the AFM images Fig. 4, section 3.4). Similar results were reported by Gutiérrez and González (2017) for films prepared from native plantain flour containing different concentrations of aloe vera gel.

The SEM images of the cryo-fractured surfaces of the films are shown in Fig. 6: all were mainly amorphous. This agrees with the XRD diffractograms of the developed films. The SEM images of the bionanocomposite films showed that incorporating the nano-fillers into the TPS matrix did not affect their morphology. Nevertheless, it should be noted that the extrusion conditions resulted in the complete gelatinization of the starch, demonstrated by the fact that morphological characteristics similar to the starch granules were not observed. This is important to note because not all extrusion conditions achieve total starch gelatinization (Li et al., 2011).

\subsection{Thickness (e)}

Several authors have observed significant differences in the thicknesses of starch-based films brought about by their physicochemical properties (Biduski et al., 2017). However, no significant differences ( $p \geq 0.05$ ) in the thicknesses (approx. $0.90 \mathrm{~mm}$ ) of the films evaluated in this study were observed (Table 1). This means that the density values obtained do not affect the relationships between the different films as regards the mass or the opacity (positively correlated to the transmitted absorbance), and it also means that the maximum stress $\left(\sigma_{m}\right)$ can be directly related to the maximum force applied to these films. A more exhaustive discussion of these properties is provided in the following sections.

\subsection{Density $(\rho)$}

Table 1 shows the densities of the films studied. As expected, all the bionanocomposite films showed higher density values than the TPS film. Slavutsky et al. (2012) obtained similar densities (from $1.32 \mathrm{~g} / \mathrm{cm}^{3}$ to $1.63 \mathrm{~g} / \mathrm{cm}^{3}$ ) for starch-clay nanocomposite films containing different concentrations of clay. However, there were no significant differences ( $p \geq 0.05$ ) among the density values of the
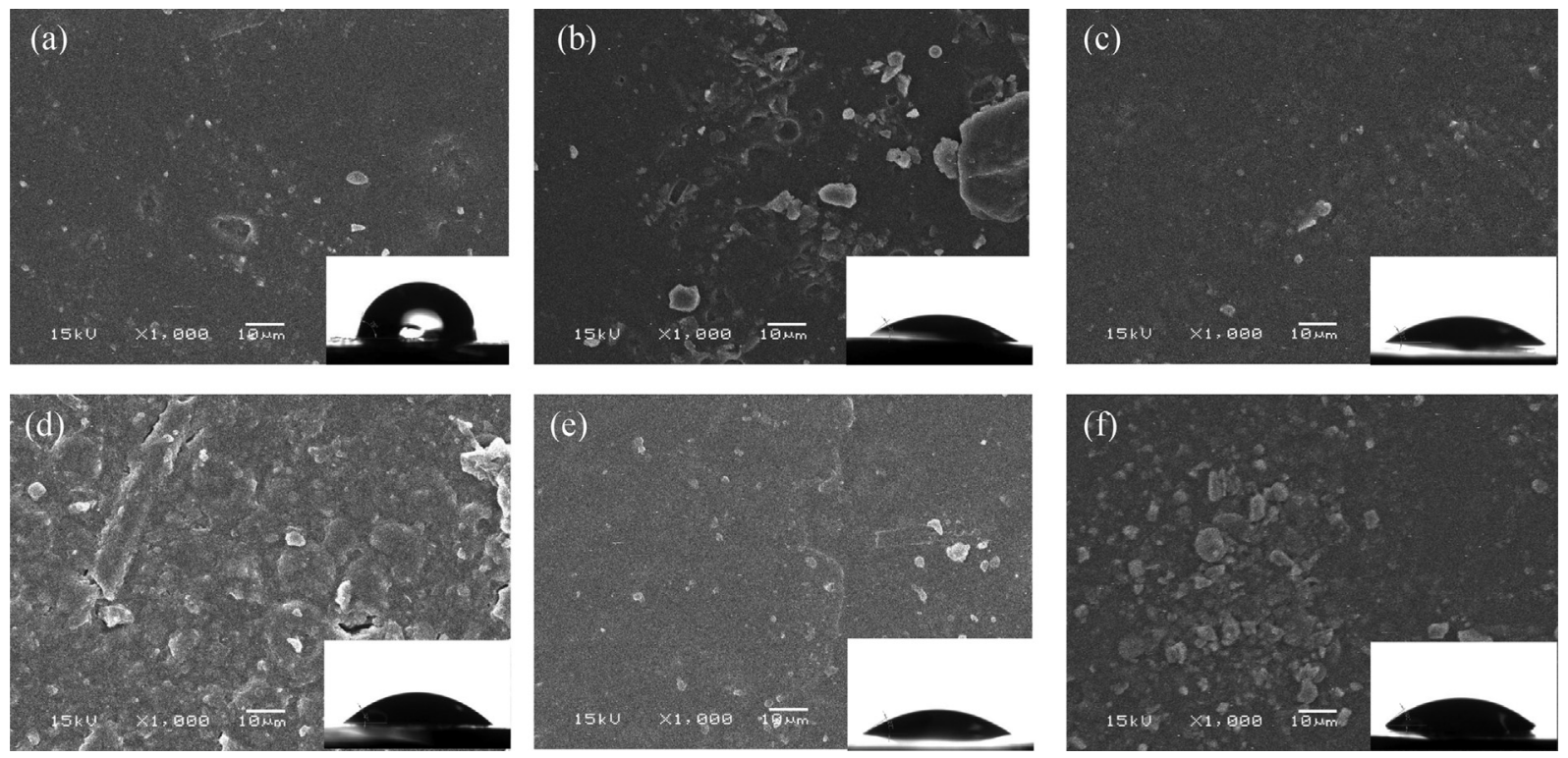

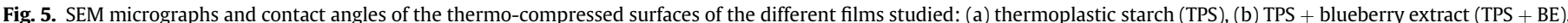

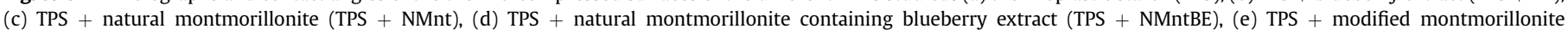
(TPS + MMnt), and (f) TPS + modified montmorillonite containing blueberry extract (TPS + MMntBE). 

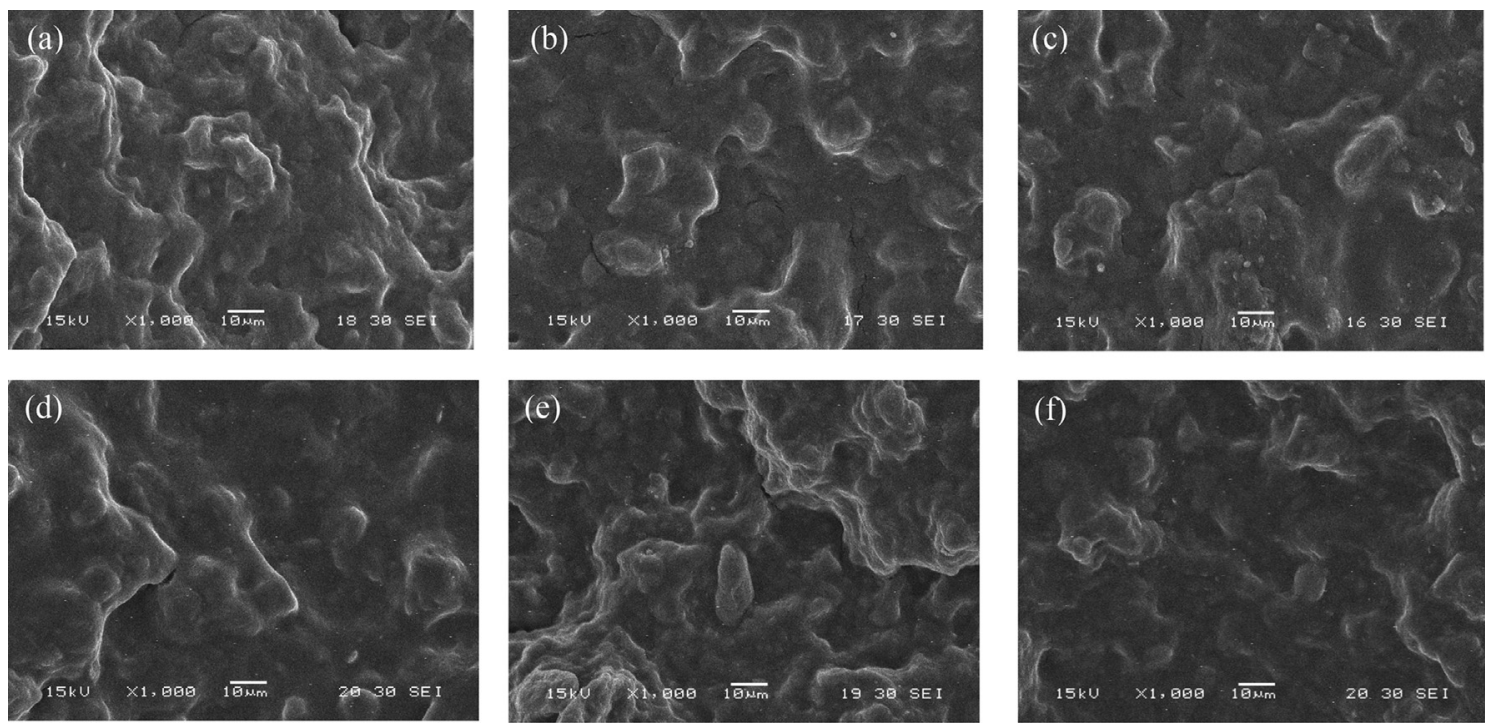

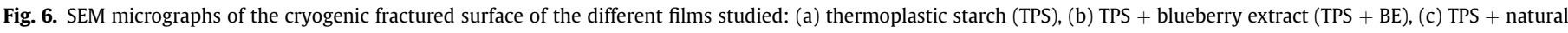

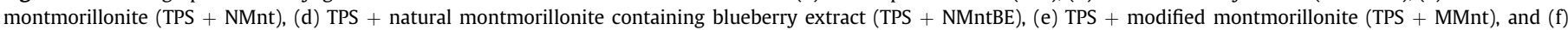
TPS + modified montmorillonite containing blueberry extract (TPS + MMntBE)

formulated nanocomposite films. Pelissari, Andrade-Mahecha, Sobral, \& Menegalli (2013) and Gutiérrez (2017b) suggested that the density of starch-based films depends on the molecular weight of the polymer, the type of polymer structure, and interactions between the constituents of the films. In this study, the TPS + BE film was 1.15 times denser than the TPS film. This could indicate that the plasticizing effect governing the properties of the TPS $+\mathrm{BE}$ film promotes attractive hydrogen bond interactions between the starch chains and the polyphonolytic extract (BE: 100\% anthocyanin). The concentration of starch macromolecules per unit volume would thus be greater, thereby increasing the density of this film. Similar behavior was observed by Siripatrawan and Harte (2010) for active films prepared from chitosan with added green tea extract.

Modifying the nano-filler (MMnt) did not affect the density values of the films compared to those made with the natural nanofiller (NMnt) (TPS + NMnt vs TPS + MMnt). Nevertheless, a significant increase $(\mathrm{p} \leq 0.05)$ in the density of the TPS + NMntBE film was observed in comparison with the TPS + NMnt film (TPS + NMntBE $>$ TPS + NMnt). This is possibly related to the wider interlayer spacing of the NMntBE nano-filler (20.5 $\AA$ ) compared to the NMnt nano-filler (18.6 ̊̊). A higher number of starch chains could be accommodated within the interlayer spacing of the NMntBE nano-filler thus generating high density sites within the material. In addition, the BE nano-packaged within the natural nano-filler could act in the same way as the TPS + BE film (plasticizing effect). However, there were no significant differences ( $p \geq 0.05$ ) in the densities of films containing the modified nanofiller with or without BE nano-packed between the layers (TPS + MMnt vs TPS + MMntBE).

\subsection{Opacity}

The opacity values of the different systems studied are shown in Table 1. The films developed showed the following ascending order of opacity: TPS $(0.094)<$ TPS + MMntBE $(0.112)<$ TPS + MMnt $(0.119)<\mathrm{TPS}+\mathrm{NMnt}(0.123)=\mathrm{TPS}+\mathrm{NMntBE}(0.123)<\mathrm{TPS}+\mathrm{BE}$ (0.133). As expected the TPS film was the least opaque (i.e. most transparent) of all the films tested. Similar results were reported by Slavutsky et al. (2012) for starch-clay nanocomposite films. According to Sukhija et al. (2016) opaque packaging materials can protect food susceptible to oxidative degradation catalyzed by UV radiation. Thus the bionanocomposite films developed here, in particular the TPS + BE film (most opaque), could be useful for preserving the organolectic quality of foods such as those rich in polyunsaturated fatty acids, vitamins, antioxidants and pigments.

Because there were no significant differences $(p \geq 0.05)$ in the thicknesses of the films studied, variations in the opacity values could be directly related to the chemical interactions that took place between the TPS matrix and the nano-fillers. Slavutsky et al. (2012) indicated that differences in opacity in nanocomposite thermoplastic materials obtained from starch-clay are due to differences in the intercalation, exfoliation and orientation of the nano-clays within the film matrices. Specifically, a greater degree of exfoliation and the parallel orientation of the nano-clays within the TPS matrix results in less opaque (more transparent) materials (Slavutsky et al., 2012). The opacity results thus suggest that the degree of exfoliation and parallel orientation of the nano-fillers within the TPS matrix was greater when the modified nano-clays were used as fillers rather than the un-modified ones. These results are consistent with those of the X-ray diffraction - XRD analyses (section 3.1). The greater number of hydrogen bond interactions between the modified nano-filler and the matrix predicted by the TGA results (section 3.2) also agrees with these results.

Thus, the previously analyzed results and opacity values reported here suggest that the nano-packaged BE improves the exfoliation and orientation of the modified nano-filler within the TPS matrix. This, however, was not the case for the natural nanofiller where the nano-packed BE did not affect the opacity values (no significant differences ( $\mathrm{p} \geq 0.05$ ) were found between the opacity values of the TPS + NMnt and TPS + NMntBE films).

\subsection{Uniaxial tensile tests}

The stress-strain curves of each film system studied are shown in appendix B. A small linear zone followed by a nonlinear zone until breaking point was observed. Similar behavior for corn starchbased films has been reported elsewhere in the literature (Ghanbarzadeh, Almasi, \& Entezami, 2011).

Table 2 shows the values for the uniaxial tensile strength 
Table 2

Parameters of the uniaxial tensile strength tests: Young's modulus $(E)$, maximum stress $\left(\sigma_{m}\right)$, strain at break $\left(\varepsilon_{b}\right)$ and toughness $(T)$.

\begin{tabular}{lllll}
\hline Material & $E(\mathrm{KPa})$ & $\sigma_{m}(\mathrm{MPa})$ & $\varepsilon_{b}(\%)$ & $T\left(\mathrm{x} 10^{3}\right)\left(\mathrm{J} / \mathrm{m}^{3}\right)$ \\
\hline TPS & $39.0 \pm 0.9^{\mathrm{d}}$ & $0.38 \pm 0.04^{\mathrm{d}}$ & $13.5 \pm 0.7^{\mathrm{a}}$ & $3.1 \pm 0.3^{\mathrm{b}, \mathrm{c}}$ \\
TPS + BE & $13.5 \pm 0.7^{\mathrm{a}}$ & $0.16 \pm 0.01^{\mathrm{a}}$ & $14.7 \pm 0.5^{\mathrm{b}, \mathrm{a}}$ & $1.4 \pm 0.1^{\mathrm{a}}$ \\
TPS + NMnt & $17 \pm 2^{\mathrm{b}, \mathrm{a}}$ & $0.23 \pm 0.02^{\mathrm{c}}$ & $19 \pm 2^{\mathrm{c}}$ & $2.7 \pm 0.6^{\mathrm{b}}$ \\
TPS + NMntBE & $16 \pm 2^{\mathrm{a}}$ & $0.19 \pm 0.01^{\mathrm{b}, \mathrm{a}}$ & $19.4 \pm 0.2^{\mathrm{c}}$ & $2.1 \pm 0.1^{\mathrm{b}}$ \\
TPS + MMnt & $20 \pm 6^{\mathrm{a}}$ & $0.18 \pm 0.02^{\mathrm{a}}$ & $13.4 \pm 0.3^{\mathrm{a}}$ & $1.6 \pm 0.1^{\mathrm{a}}$ \\
TPS + MMntBE & $26.4 \pm 0.2^{\mathrm{c}}$ & $0.23 \pm 0.02^{\mathrm{c}}$ & $12.6 \pm 0.7^{\mathrm{a}}$ & $1.7 \pm 0.2^{\mathrm{a}}$ \\
\hline
\end{tabular}

Equal letters in the same column indicate no statistically significant difference $(\mathrm{p} \leq 0.05)$.

Thermoplastic starch (TPS), TPS + blueberry extract (TPS + BE), TPS + natura montmorillonite (TPS + NMnt), TPS + natural montmorillonite containing blueberry extract (TPS + NMntBE), TPS + modified montmorillonite (TPS + MMnt) and TPS + modified montmorillonite containing blueberry extract (TPS + MMntBE).

parameters tested for each film system: Young's modulus $(E)$, maximum stress $\left(\sigma_{m}\right)$, strain at break $\left(\varepsilon_{b}\right)$ and toughness $(T)$. The TPS + BE film showed slightly higher $\varepsilon_{b}$ values than the TPS film, although this was not statistically significant $(p \geq 0.05)$. This would be in line with the plasticizer effect suggested for the TPS + BE film. The TPS + BE film also had lower $E, \sigma_{m}$, and $T$ values than the TPS film demonstrating the effect of incorporating BE into the TPS matrix. Similar results were reported by Medina Jaramillo et al. (2015) for cassava starch-based films containing yerba mate extract.

The presence of the modified nano-clay filler (MMnt) caused a decrease in the $\sigma_{m}, \varepsilon_{b}$, and $T$ values of the TPS + MMnt film compared to those of the film prepared using natural nano-clay as the filler (TPS + NMnt) film. However, the $E$ values were slightly, although non-significantly ( $\mathrm{p} \geq 0.05$ ), higher in the TPS + MMnt film compared to the TPS + NMnt film.

The film containing the modified nano-clay plus the nanopacked BE (TPS + MMntBE) showed higher $E$, and $\sigma_{m}$ values, but lower $\varepsilon_{b}$, and $T$ values compared to the film prepared from the natural nano-clay plus BE (TPS + NMntBE film). However, the incorporation of $\mathrm{BE}$ into the NMnt nano-filler (NMntBE) did not significantly alter ( $\mathrm{p} \geq 0.05)$ the $E, \varepsilon_{b}$, and $T$ values of the resulting TPS + NMntBE film compared to the films made with the NMnt nano-filler without BE (TPS + NMnt) film; although a significant ( $\mathrm{p} \leq 0.05)$ decrease in the $\sigma_{m}$ value was observed for the TPS + NMntBE film compared to the TPS + NMnt film.

Finally, the films containing the MMnt nano-filler with nanopacked BE (TPS + MMntBE) showed significantly higher $(\mathrm{p} \leq 0.05) E$, and $\sigma_{m}$ values compared to the films with the MMnt nano-filler but without BE (TPS + MMnt), however, no significant change was observed for the $\varepsilon_{b}$, and $T$ values $(\mathrm{p} \geq 0.05$ ) between these two film types.

These results show that the incorporation of more exfoliated nano-fillers, i.e. those with a greater interlayer spacing in the TPS matrix, led to an increase in the $E$ values of the bionanocomposite films developed. This demonstrates that more and stronger nanofiller/starch interactions were generated, resulting in the

\begin{tabular}{|c|c|c|c|}
\hline Films evaluated & pH 1 & pH 7 & pH 13 \\
\hline TPS & & & \\
\hline TPS + BE & & & \\
\hline TPS + NMnt & & & \\
\hline TPS + NMntBE & & & \\
\hline TPS + MMnt & & & \\
\hline TPS + MMntBE & & & \\
\hline
\end{tabular}

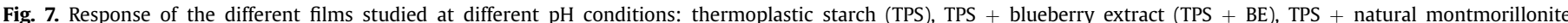

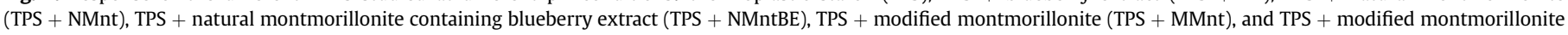
containing blueberry extract (TPS + MMntBE). 
production of more resistant (stiffer) and more brittle materials (fragile mechanical behavior). However, the $\sigma_{m}$ values of the materials tested did not show a clear trend in relation to the degree of interlayer spacing of the nano-filler employed.

\subsection{Response to $\mathrm{pH}$ changes}

Fig. 7 shows the images of the responses of the films assayed at different $\mathrm{pH}$ values. The incorporation of anthocyanin extracts obtained from different vegetable sources has enabled the development of edible and intelligent ( $\mathrm{pH}$-sensitive) films using the casting methodology (Choi et al., 2017; Liu et al., 2017; Luchese et al., 2015; Ma \& Wang, 2016; Pereira et al., 2015; Prietto et al., 2017; Yoshida et al., 2014). BE (100\% anthocyanin) has recently been shown to change color at different $\mathrm{pH}$ values due to the structural variations occurring within the anthocyanin molecules (Gutiérrez, Ponce, et al., 2017). Nonetheless, the TPS + BE film obtained through extrusion in this study was not $\mathrm{pH}$-sensitive. The conditions under which this process takes place, such as the shear forces and high pressures within the extruder, may lead to the decomposition or degradation of the pigment. This could represent a limitation of the use of natural pigments for the development of $\mathrm{pH}$-sensitive food packaging on an industrial scale.

Similarly, our research group was able to develop $\mathrm{pH}$-sensitive nano-clays prepared from natural and modified Mnt with added BE (Gutiérrez, Ponce, et al., 2017). Our idea was to use these nanoclays as fillers in TPS matrices as they are known to improve the performance of these types of material, in order to obtain $\mathrm{pH}-$ sensitive bionanocomposite films with enhanced physicochemical and mechanical properties. Unfortunately, however, in this regard the incorporation of the $\mathrm{pH}$-sensitive nano-fillers was not successful even though the diffusion of the pigment towards the medium has been previously reported by us elsewhere (Gutiérrez, Ponce, et al., 2017). This may be because the nano-packed pigment is uncovered by the exfoliation of the nano-fillers during their incorporation into the TPS matrix, thus exposing the anthocyanins to the processing conditions. The effect of the nano-clays as protection for the pigment would thus be lost during TPS manufacture.

\section{Conclusions}

This study was undertaken with the idea of incorporating intelligent ( $\mathrm{pH}$-sensitive) nano-clays into thermoplastic starch TPS matrices in order to serve a dual purpose: 1 ) to develop intelligent (pH-sensitive) bionanocomposite films; and 2) to obtain bionanocomposite films with improved properties. Unfortunately the first objective was not achieved. Regarding the second objective, however, we found that the more exfoliated nano-clays, i.e. those with a greater interlayer spacing, enabled the production of more resistant (stiffer) but more brittle materials (fragile mechanical behavior). Finally, the exfoliation of the nano-clays leaves the pigment unprotected. There is thus a balance between ensuring the exfoliation of the nano-clays, together with the complete gelatinization of the starch and the protection of the pigment, which has yet to be achieved.

\section{Conflicts of interest}

The authors declare no conflict of interest.

\section{Acknowledgements}

The authors would like to thank the Consejo Nacional de Investigaciones Científicas y Técnicas (CONICET) (Postdoctoral fellowship internal PDTS-Resolution 2417), Universidad Nacional de Mar del Plata (UNMdP) for financial support. Also, Dr. Mirian Carmona-Rodríguez for her valuable contribution. We are also very grateful to Dr. Gema González and M.Sc. Antonio Monsalve from the Venezuelan Institute for Scientific Research (IVIC), for allowing us to carry out the acquisition of AFM images in their laboratory, and to M.Sc. Kelvia Álvarez for performing the AFM study. Many thanks also to Andres Torres Nicolini for all the assistance he provided in this research.

\section{Appendix A and B. Supplementary data}

Supplementary data related to this article can be found at https://doi.org/10.1016/j.foodhyd.2017.10.017.

\section{References}

Abreu, A. S., Oliveira, M., de Sá, A., Rodrigues, R. M., Cerqueira, M. A., Vicente, A. A., et al. (2015). Antimicrobial nanostructured starch based films for packaging. Carbohydrate Polymers, 129, 127-134. https://doi.org/10.1016/j.carbpol.2015.04 021.

Alam, M. S., Pathania, S., \& Sharma, A. (2016). Optimization of the extrusion process for development of high fibre soybean-rice ready-to-eat snacks using carrot pomace and cauliflower trimmings. LWT - Food Science and Technology, 74, 135-144. https://doi.org/10.1016/j.lwt.2016.07.031.

Aouada, F. A., Mattoso, L. H. C., \& Longo, E. (2013). Enhanced bulk and superficial hydrophobicities of starch-based bionanocomposites by addition of clay. Industrial Crops and Products, 50, 449-455. https://doi.org/10.1016/j.indcrop.2013. 07.058 .

Biduski, B., da Silva, F. T., da Silva, W. M., de Mello El Halal, S. L., Pinto, V. Z., Dias, A. R. G., et al. (2017). Impact of acid and oxidative modifications, single or dual, of sorghum starch on biodegradable films. Food Chemistry, 214, 53-60. https://doi.org/. https://doi.org/10.1016/j.foodchem.2016.07.039.

Boethling, R. (1984). Environmental fate and toxicity in wastewater treatment of quaternary ammonium surfactants. Water Research, 18(9), 1061-1076. https:// doi.org/10.1016/0043-1354(84)90220-3.

von Borries-Medrano, E., Jaime-Fonseca, M. R., \& Aguilar-Méndez, M. A. (2016). Starch-guar gum extrudates: Microstructure, physicochemical properties and in-vitro digestion. Food Chemistry, 194, 891-899. https://doi.org/10.1016/j. foodchem.2015.08.085.

Breakwell, I. K., Homer, J., Lawrence, M. A. M., \& McWhinnie, W. R. (1995). Studies of organophilic clays: The distribution of quaternary ammonium compounds on clay surfaces and the role of impurities. Polyhedron, 14(17-18), 2511-2518. https://doi.org/10.1016/0277-5387(95)00053-U.

Burros, B. C., Young, L. A., \& Carroad, P. A. (1987). Kinetics of corn meal gelatinization at high temperature and low moisture. Journal of Food Science, 52(5) 1372-1376. https://doi.org/10.1111/j.1365-2621.1987.tb14085.x.

CAIP. Cámara Argentina de la Industria Plástica. (2010). Anuario Estadístico de la Industria Plástica Argentina. Retrieved from https://caip.org.ar/anuarioestadistico/.

Choi, I., Lee, J. Y., Lacroix, M., \& Han, J. (2017). Intelligent pH indicator film composed of agar/potato starch and anthocyanin extracts from purple sweet potato. Food Chemistry, 218, 122-128. https://doi.org/10.1016/j.foodchem.2016.09.050.

Cyras, V. P., Manfredi, L. B., Ton-That, M.-T., \& Vázquez, A. (2008). Physical and mechanical properties of thermoplastic starch/montmorillonite nanocomposite films. Carbohydrate Polymers, 73(1), 55-63. https://doi.org/10.1016/j.carbpol. 2007.11.014.

Dai, H., Chang, P. R., Geng, F., Yu, J., \& Ma, X. (2010). Preparation and properties of starch-based film using N,N-bis(2-hydroxyethyl)formamide as a new plasticizer. Carbohydrate Polymers, 79(2), 306-311. https://doi.org/10.1016/j.carbpol. 2009.08.012.

Du, Q., Freysz, E., \& Shen, Y. R. (1994a). Surface vibrational spectroscopic studies of hydrogen bonding and hydrophobicity. Science, 264(5160), 826-828. Retrieved from http://www.jstor.org/stable/2884027.

Du, Q., Freysz, E., \& Shen, Y. R. (1994b). Vibrational spectra of water molecules at quartz/water interfaces. Physical Review Letters, 72(2), 238-241. https://doi.org/ 10.1103/PhysRevLett.72.238.

Du, Q., Superfine, R., Freysz, E., \& Shen, Y. R. (1993). Vibrational spectroscopy of water at the vapor/water interface. Physical Review Letters, 70(15), 2313-2316 https://doi.org/10.1103/PhysRevLett.70.2313.

FAO. Food and Agriculture Organization of the United Nations. (2012). Pérdidas y desperdicio de alimentos en el mundo-Alcance, causas y prevención. Retrieved from http://www.fao.org/docrep/016/i2697s/i2697s.pdf.

García-Tejeda, Y. V., López-González, C., Pérez-Orozco, J. P., Rendón-Villalobos, R. Jiménez-Pérez, A., Flores-Huicochea, E., ... Bastida, C. A. (2013). Physicochemical and mechanical properties of extruded laminates from native and oxidized banana starch during storage. LWT - Food Science and Technology, 54(2), 447-455. https://doi.org/10.1016/j.lwt.2013.05.041.

Ghanbarzadeh, B., Almasi, H., \& Entezami, A. A. (2011). Improving the barrier and mechanical properties of corn starch-based edible films: Effect of citric acid and 
carboxymethyl cellulose. Industrial Crops and Products, 33(1), 229-235. https:// doi.org/10.1016/j.indcrop.2010.10.016.

Gutiérrez, T. J. (2017a). Surface and nutraceutical properties of edible films made from starchy sources with and without added blackberry pulp. Carbohydrate Polymers, 165, 169-179. https://doi.org/10.1016/j.carbpol.2017.02.016.

Gutiérrez, T. J. (2017b). Effects of exposure to pulsed light on molecular aspects of edible films made from cassava and taro starch. Innovative Food Science \& Emerging Technologies, 41, 387-396. https://doi.org/10.1016/j.ifset.2017.04.014.

Gutiérrez, T. J., \& Alvarez, V. A. (2017). Cellulosic materials as natural fillers in starch-containing matrix-based films: A review. Polymer Bulletin, 74(6), 2401-2430. https://doi.org/10.1007/s00289-016-1814-0.

Gutiérrez, T. J., \& González, G. (2016). Effects of exposure to pulsed light on surface and structural properties of edible films made from cassava and taro starch. Food and Bioprocess Technology, 9(11), 1812-1824. https://doi.org/10.1007/ s11947-016-1765-3.

Gutiérrez, T. J., \& González, G. (2017). Effect of cross-linking with Aloe vera gel on surface and physicochemical properties of edible films made from plantain flour. Food Biophysics, 12(1), 11-22. https://doi.org/10.1007/s11483-016-9458-z.

Gutiérrez, T. J., González Seligra, P., Medina Jaramillo, C., Famá, L., \& Goyanes, S. (2017a). Effect of filler properties on the antioxidant response of thermoplastic starch composites. In V. Kumar Thakur, M. K. Thakur, \& M. R. Kessler (Eds.), Vol. 1. Handbook of composites from renewable materials, structure and chemistry (pp. 337-369). Chennai: John Wiley \& Sons. Retrieved from http://www.wiley.com/ WileyCDA/WileyTitle/productCd-1119223628.html.

Gutiérrez, T. J., Guarás, M. P., \& Alvarez, V. A. (2017b). Reactive extrusion for the production of starch-based biopackaging. In M. A. Masuelli (Ed.), Biopackaging. Miami: CRC Press, Taylor \& Francis Group. Retrieved from https://www. crcpress.com/Biopackaging/Masuelli/p/book/9781498749688.

Gutiérrez, T. J., Guzmán, R., Medina Jaramillo, C., \& Famá, L. (2016a). Effect of beet flour on films made from biological macromolecules: Native and modified plantain flour. International Journal of Biological Macromolecules, 82, 395-403. https://doi.org/10.1016/j.ijbiomac.2015.10.020.

Gutiérrez, T. J., Morales, N. J., Pérez, E., Tapia, M. S., \& Famá, L. (2015a). Physicochemical properties of edible films derived from native and phosphated cushcush yam and cassava starches. Food Packaging and Shelf Life, 3, 1-8. https://doi. org/10.1016/j.fpsl.2014.09.002.

Gutiérrez, T. J., Ollier, R., \& Alvarez, V. A. (2018). Surface properties of thermoplastic starch materials reinforced with natural fillers. In V. K. Thakur, \& M. K. Thaku (Eds.), Functional biopolymers. Springer International Publishing. https://doi. org/10.1007/978-3-319-66417-0_5.

Gutiérrez, T. J., Ponce, A. G., \& Alvarez, V. A. (2017c). Nano-clays from natural and modified montmorillonite with and without added blueberry extract for active and intelligent food nanopackaging materials. Materials Chemistry and Physics, 194, 283-292. https://doi.org/10.1016/j.matchemphys.2017.03.052.

Gutiérrez, T. J., Suniaga, J., Monsalve, A., \& García, N. L. (2016b). Influence of beet flour on the relationship surface-properties of edible and intelligent films made from native and modified plantain flour. Food Hydrocolloids, 54, 234-244. https://doi.org/10.1016/j.foodhyd.2015.10.012.

Gutiérrez, T. J., Tapia, M. S., Pérez, E., \& Famá, L. (2015b). Edible films based on native and phosphated 80:20 waxy:normal corn starch. Starch - Stärke, 67(1-2) 90-97. https://doi.org/10.1002/star.201400164.

Han, J. H., \& Floros, J. D. (1997). Casting antimicrobial packaging films and measuring their physical properties and antimicrobial activity. Journal of Plastic Film \& Sheeting, 13(4), 287-298. https://doi.org/10.1177/875608799701300405.

Iman, M., \& Maji, T. K. (2012). Effect of crosslinker and nanoclay on starch and jute fabric based green nanocomposites. Carbohydrate Polymers, 89(1), 290-297. https://doi.org/10.1016/j.carbpol.2012.03.012.

ISO 527-2. (2012). Determination of tensile properties of plastics. Retrieved from https://www.iso.org/obp/ui/\#iso:std:56046:en.

Kampeerapappun, P., Aht-ong, D., Pentrakoon, D., \& Srikulkit, K. (2007). Preparation of cassava starch/montmorillonite composite film. Carbohydrate Polymers, 67(2), 155-163. https://doi.org/10.1016/j.carbpol.2006.05.012.

Karbowiak, T., Debeaufort, F., Champion, D., \& Voilley, A. (2006). Wetting properties at the surface of iota-carrageenan-based edible films. Journal of Colloid and Interface Science, 294(2), 400-410. https://doi.org/10.1016/j.jcis.2005.07.030.

Kozak, M., \& Domka, L. (2004). Adsorption of the quaternary ammonium salts on montmorillonite. Journal of Physics and Chemistry of Solids, 65(2-3), 441-445. https://doi.org/10.1016/j.jpcs.2003.09.015.

Lee, C., McCammon, J. A., \& Rossky, P. J. (1984). The structure of liquid water at an extended hydrophobic surface. The Journal of Chemical Physics, 80(9), 4448-4455. https://doi.org/10.1063/1.447226.

Li, M., Liu, P., Zou, W., Yu, L., Xie, F., Pu, H., ... Chen, L. (2011). Extrusion processing and characterization of edible starch films with different amylose contents. Journal of Food Engineering, 106(1), 95-101. https://doi.org/10.1016/j.jfoodeng. 2011.04.021.

Liu, B., Xu, H., Zhao, H., Liu, W., Zhao, L., \& Li, Y. (2017). Preparation and characterization of intelligent starch/PVA films for simultaneous colorimetric indication and antimicrobial activity for food packaging applications. Carbohydrate Polymers, 157, 842-849. https://doi.org/10.1016/j.carbpol.2016.10.067.

Luchese, C. L., Frick, J. M., Patzer, V. L., Spada, J. C., \& Tessaro, I. C. (2015). Synthesis and characterization of biofilms using native and modified pinhão starch. Food Hydrocolloids, 45, 203-210. https://doi.org/10.1016/j.foodhyd.2014.11.015.

Luchese, C. L., Garrido, T., Spada, J. C., Tessaro, I. C., \& de la Caba, K. (2017). Development and characterization of cassava starch films incorporated with blueberry pomace. International Journal of Biological Macromolecules. https://doi.org https://doi.org/10.1016/j.ijbiomac.2017.08.083.

Ludueña, L., Morán, J., \& Alvarez, V. (2015). Biodegradable polymer/clay nanocomposites. In V. K. Thakur, \& M. K. Thakur (Eds.), Eco-friendly polymer nanocomposites: Processing and properties (pp. 109-135). New Delhi: Springer India. https://doi.org/10.1007/978-81-322-2470-9_4.

Mali, S., Grossmann, M. V. E., Garcia, M. A., Martino, M. N., \& Zaritzky, N. E. (2002). Microstructural characterization of yam starch films. Carbohydrate Polymers, 50(4), 379-386. https://doi.org/10.1016/S0144-8617(02)00058-9.

Ma, Q., \& Wang, L. (2016). Preparation of a visual $\mathrm{pH}$-sensing film based on tara gum incorporating cellulose and extracts from grape skins. Sensors and Actuators B: Chemical, 235, 401-407. https://doi.org/10.1016/j.snb.2016.05.107.

Medina Jaramillo, C., González Seligra, P., Goyanes, S., Bernal, C., \& Famá, L. (2015). Biofilms based on cassava starch containing extract of yerba mate as antioxidant and plasticizer. Starch - Stärke, 67(9-10), 780-789. https://doi.org/10.1002/star. 201500033.

Medina Jaramillo, C., Gutiérrez, T. J., Goyanes, S., Bernal, C., \& Famá, L. (2016). Biodegradability and plasticizing effect of yerba mate extract on cassava starch edible films. Carbohydrate Polymers, 151, 150-159. https://doi.org/10.1016/j. carbpol.2016.05.025.

Ojagh, S. M., Rezaei, M., Razavi, S. H., \& Hosseini, S. M. H. (2010). Development and evaluation of a novel biodegradable film made from chitosan and cinnamon essential oil with low affinity toward water. Food Chemistry, 122(1), 161-166. https://doi.org/10.1016/j.foodchem.2010.02.033.

Pandey, J. K., \& Singh, R. P. (2005). Green nanocomposites from renewable resources: Effect of plasticizer on the structure and material properties of clayfilled starch. Starch-Stärke, 57(1), 8-15. https://doi.org/10.1002/star.200400313.

Pelissari, F. M., Andrade-Mahecha, M. M., Sobral, P. J., do, A., \& Menegalli, F. C. (2013). Comparative study on the properties of flour and starch films of plantain bananas (Musa paradisiaca). Food Hydrocolloids, 30(2), 681-690. https://doi.org/ 10.1016/j.foodhyd.2012.08.007.

Pereira, V. A., de Arruda, I. N. Q., \& Stefani, R. (2015). Active chitosan/PVA films with anthocyanins from Brassica oleraceae (Red Cabbage) as Time-Temperature Indicators for application in intelligent food packaging. Food Hydrocolloids, 43 180-188. https://doi.org/10.1016/j.foodhyd.2014.05.014.

Pérez, E., Pérez, C. J., Alvarez, V. A., \& Bernal, C. (2013). Fracture behavior of a commercial starch/polycaprolactone blend reinforced with different layered silicates. Carbohydrate Polymers, 97(2), 269-276. https://doi.org/10.1016/j. carbpol.2013.04.099.

Prietto, L., Mirapalhete, T. C., Pinto, V. Z., Hoffmann, J. F., Vanier, N. L., Lim, L.-T., ... da Rosa Zavareze, E. (2017). pH-sensitive films containing anthocyanins extracted from black bean seed coat and red cabbage. LWT - Food Science and Technology, 80, 492-500. https://doi.org/10.1016/j.lwt.2017.03.006.

Rhim, J.-W. (2011). Effect of clay contents on mechanical and water vapor barrier properties of agar-based nanocomposite films. Carbohydrate Polymers, 86(2), 691-699. https://doi.org/10.1016/j.carbpol.2011.05.010.

Romero-Bastida, C. A., Tapia-Blácido, D. R., Méndez-Montealvo, G., Bello-Pérez, L. A., Velázquez, G., \& Alvarez-Ramirez, J. (2016). Effect of amylose content and nanoclay incorporation order in physicochemical properties of starch/montmorillonite composites. Carbohydrate Polymers, 152, 351-360. https://doi.org/ 10.1016/j.carbpol.2016.07.009.

Siripatrawan, U., \& Harte, B. R. (2010). Physical properties and antioxidant activity of an active film from chitosan incorporated with green tea extract. Food Hydrocolloids, 24(8), 770-775. https://doi.org/10.1016/j.foodhyd.2010.04.003.

Slavutsky, A. M., Bertuzzi, M. A., \& Armada, M. (2012). Water barrier properties of starch-clay nanocomposite films. Brazilian Journal of Food Technology, 15, 208-218. Retrieved from http://www.scielo.br/scielo.php?script=sci arttext\&pid=S1981-67232012000300004\&nrm=iso.

Sukhija, S., Singh, S., \& Riar, C. S. (2016). Analyzing the effect of whey protein concentrate and psyllium husk on various characteristics of biodegradable film from lotus (Nelumbo nucifera) rhizome starch. Food Hydrocolloids, 60, 128-137. https://doi.org/10.1016/j.foodhyd.2016.03.023.

Talja, R. A., Helén, H., Roos, Y. H., \& Jouppila, K. (2007). Effect of various polyols and polyol contents on physical and mechanical properties of potato starch-based films. Carbohydrate Polymers, 67(3), 288-295. https://doi.org/. https://doi.org/ 10.1016/j.carbpol.2006.05.019.

Vasanthan, T., \& Hoover, R. (1992). Effect of defatting on starch structure and physicochemical properties. Food Chemistry, 45(5), 337-347. https://doi.org/10. 1016/0308-8146(92)90034-Y.

Vazquez, A., Cyras, V. P., Alvarez, V. A., \& Moran, J. I. (2012). Starch/clay nano-biocomposites. In L. Avérous, \& E. Pollet (Eds.), Environmental silicate nano-biocomposites (pp. 287-321). London: Springer London. https://doi.org/10.1007/ 978-1-4471-4108-2 11 .

Veiga-Santos, P., Oliveira, L. M., Cereda, M. P., \& Scamparini, A. R. P. (2007). Sucrose and inverted sugar as plasticizer. Effect on cassava starch?gelatin film mechanical properties, hydrophilicity and water activity. Food Chemistry, 103(2), 255-262. https://doi.org/10.1016/j.foodchem.2006.07.048.

Vogler, E. A. (1998). Structure and reactivity of water at biomaterial surfaces. Advances in Colloid and Interface Science, 74(1-3), 69-117. https://doi.org/10.1016/ S0001-8686(97)00040-7.

Vogler, E. A., Graper, J. C., Harper, G. R., Sugg, H. W., Lander, L. M., \& Brittain, W. J. (1995). Contact activation of the plasma coagulation cascade. I. Procoagulant surface chemistry and energy. Journal of Biomedical Materials Research, 29(8), 1005-1016. https://doi.org/10.1002/jbm.820290813.

Wilpiszewska, K., Antosik, A. K., \& Spychaj, T. (2015). Novel hydrophilic carboxymethyl starch/montmorillonite nanocomposite films. Carbohydrate Polymers, 
128, 82-89. https://doi.org/. https://doi.org/10.1016/j.carbpol.2015.04.023.

Xie, M., Duan, Y., Li, F., Wang, X., Cui, X., Bacha, U., .. Zhao, Z. (2017). Preparation and characterization of modified and functional starch (hexadecyl corboxymethyl starch) ether using reactive extrusion. Starch - Stärke, 69(5-6), 1600061. https:// doi.org/10.1002/star.201600061.

Xie, D. F., Martino, V. P., Sangwan, P., Way, C., Cash, G. A., Pollet, E., ... Avérous, L. (2013). Elaboration and properties of plasticised chitosan-based exfoliated nano-biocomposites. Polymer, 54(14), 3654-3662. https://doi.org/10.1016/j. polymer.2013.05.017.

Yan, Q., Hou, H., Guo, P., \& Dong, H. (2012). Effects of extrusion and glycerol content on properties of oxidized and acetylated corn starch-based films. Carbohydrate
Polymers, 87(1), 707-712. https://doi.org/10.1016/j.carbpol.2011.08.048.

Yoshida, C. M. P., Maciel, V. B. V., Mendonça, M. E. D. \& Franco, T. T. (2014). Chitosan biobased and intelligent films: Monitoring pH variations. LWT - Food Science and Technology, 55(1), 83-89. https://doi.org/10.1016/j.lwt.2013.09.015.

Zeppa, C., Gouanvé, F., \& Espuche, E. (2009). Effect of a plasticizer on the structure of biodegradable starch/clay nanocomposites: Thermal, water-sorption, and oxygen-barrier properties. Journal of Applied Polymer Science, 112(4), 2044-2056. https://doi.org/10.1002/app.29588.

Zhang, Y.-R., Wang, X.-L., Zhao, G.-M., \& Wang, Y.-Z. (2013). Influence of oxidized starch on the properties of thermoplastic starch. Carbohydrate Polymers, 96(1), 358-364. https://doi.org/10.1016/j.carbpol.2013.03.093. 